\title{
MELINDROSAS EM REVISTA: \\ GÊNERO E SOCIABILIDADES DO INÍCIO DO SÉCULO XX (RECIFE, 1919-1929)
}

\author{
MELINDROSAS ON MAGAZINES:
}

GENDER AND SOCIAL INTERACTION IN THE TWENTIES (RECIFE, 1919-1929)

\author{
alcileide Cabral do Nascimento* \\ alcileide.cabral@gmail.com \\ Alexandre Vieira da Silva Melo** \\ alexandremelo@live.com
}

RESUMO: Este artigo objetiva investigar a construção de novas formas de sociabilidades, práticas e a ressignificação do corpo feminino nos primeiros anos do Brasil República, na cidade do Recife, na década de 1920. Do ponto de vista teórico, este trabalho dialoga e se apoia nas reflexões de Joan Scott sobre o conceito de gênero e de Roger Chartier de representação. Por meio da análise de revistas publicadas na época, identificamos o quanto a melindrosa incomodava a sociedade, em um período marcado pelo fortalecimento da família nuclear burguesa e declínio da família patriarcal. As representações publicadas na imprensa maximizavam as características de um "novo padrão" adotado por mulheres e homens, na figura do almofadinha, adeptos da vida moderna. Em Recife e em outras regiões do país, o corpo se ressignificava inclusive nas noções de masculinidade e feminilidade. Ademais, o período em evidência ficou conhecido exatamente pelas modificações no que concerne às práticas sociais, e pelo advento da personagem em questão, que rompia com vários padrões da vida social.

PALAVRAS-ChAVE: Melindrosa; Sociabilidades; Relações de Gênero.

* Professora doutora em História da UFRPE.

** Mestrando do programa de pós-graduação em História Social da Cultura da UFRPE. Pesquisa financiada pelo Capes. O autor e a autora integram os Grupos de Estudos NUPEGE e GEHISC, filiados ao CNPq. 
ABSTRACT: This article aims to investigate a construction of new ways of sociability, practices and the resignifications of female body on the first years of Brazilian Republic, in Recife, in the twenties. From a theoretical point of view, this research dialogs and leans on Joan Scott's reflections about the gender concept and Roger Chartier's representation concept. Trough an analyze of magazines published on that period, we identified how much the melindrosa used to disturb the society, in a period marked by the strengthening of bourgeois nuclear family and the fall of patriarchal family. The representations published on the press maximized the characteristics of a new standard used by women and men, by the figure of almofadinha, adepts of modern life. In Recife and others country's regions, the body resignified itself including the notions of masculinity concerning the social practices, and by the advent of the character in question, that broke a lot of social life standards.

KEYWORDS: Melindrosas; Sociability; Gender Relationship.

MELINDRANDO...

Figuras interessantes, que hoje, são apenas conhecidas por fantasias carnavalescas, as melindrosas já foram reais personagens a transitar pelas urbes das primeiras décadas do século XX. Pesquisas das mais variadas acerca dos anos 1920, entretanto, não lhes deram o espaço devido, restando a elas, injustamente, um parágrafo, ou mesmo uma simples nota sem destaque. As mulheres por muito foram consideradas personagens secundárias dentro da história dos homens. Michelle Perrot fundamenta seus estudos, não trocando as mulheres de papel com os homens, mas colocando-os lado a lado, visto ser impossível se pensar em uma história em que as mulheres não participem de maneira atuante, lado a lado com os homens. Perrot ataca a maneira com que o feminino vinha sido apresentado na academia, para ela "[...] as mulheres são imaginadas, representadas, em vez de serem descritas ou contadas." (PERROT, 2007, p. 07) As pesquisas históricas mais tradicionais 
partiram de pressupostos de exclusão, minimalistas no tocante a atuação da mulher $\mathrm{O}$ panorama social e histórico que apresentavam as relegavam ao silêncio. Nós, todavia, optamos por valorizar e conhecer mais o universo feminino e sua relação com o masculino, observando essas figuras graciosas, que viveram fora das convenções de seu tempo, chamadas de melindrosas.

As pesquisas nos levaram a crer que a melindrosa foi fruto de uma série de situações sociais e culturais que se desenrolaram durante os anos do conflito europeu que findou em 1918, período denominado de "entre guerras". Os sobreviventes do combate restauravam suas cidades e enterravam seus mortos, ao mesmo tempo em que sentiam o quanto as relações humanas estavam fragilizadas. Entre a multiplicidades de emoções, pairavam mistos "[...] sentimentos como a insegurança, o medo e a esperança." (RODRIGUES, 1997, p. 07) além da modificação de valores morais, afastamento gradual aos padrões da belle époque, crescimento das cidades, e fortalecimento do individualismo. O palco urbano vivenciava o surgimento de uma nova configuração social e de uma transformação na identidade subjetiva das pessoas. A personificação das fragilidades das relações humanas, o desejo crescente de superação, o "viver intensamente o momento", e a insegurança do que se esperar do futuro, são características que refletiram diretamente no comportamento social urbano. Ao mesmo tempo, intensificava-se a produção tecnológica de maneira jamais vista, com bens de consumo desenfreadamente produzidos, novas modas e êxtase de consumir. O capitalismo fortalecia-se e encurtava as distancias entre povos de distantes fronteiras. Desta forma, apresentava-se aos mercados e, em espaços de tempo cada vez menores, as novidades desses novos tempos, incluindo os novos padrões sociais dominantes. Um estado de agitação fervilhava a mente das pessoas, a busca desenfreada por diversão, festas, danças tornaram-se método inconscientemente usado para recuperar o tempo perdido com o 
conflito. A influência desse comportamento extrapolou as fronteiras do velho continente, tal como observa Nicolau Sevcenko:

[...] nunca em nenhum período anterior tantas pessoas foram envolvidas de modo tão completo e tão rápido num processo dramático de transformação de seus hábitos cotidianos, suas convicções, seus modos de percepção e até seus reflexos instintivos, isso não só no Brasil, mas no mundo tomado agora como um todo integrado. (SEVCENKO, 1998, p. 7-8)

Gradativamente as subjetividades eram lapidadas a uma nova situação histórica. Nesse ínterim, surgem as melindrosas, que em seus corpos demonstravam o sentimento de viver a vida. Eram moças com aparência de crianças, de personalidade forte, que valorizavam ainda mais a maquiagem, e desafiavam - tal como os almofadinhas ${ }^{1}$, - as convenções sociais correntes. Surgiram em diferentes pontos do globo quase que ao mesmo tempo, cada uma atendia a condições culturais de seus locais. Consideramos as melindrosas como símbolo máximo da modernidade ansiada pelo início do século XX: seres emblemáticos, andróginos, que apresentam de maneira formidável a adesão aos desígnios de uma sociedade moderna. Susan Besse observa que [...] enquanto a modernização e o embelezamento dos centros urbanos que proliferavam, exibiam riqueza acumulada e progresso tecnológico, as imagens das moças independentes que trabalhavam fora e das melindrosas sensuais simbolizavam a mudança nas relações sociais. (BESSE, 1999, p. 37) Caracterizava ela, também, uma ruptura com a condição tradicional dos gêneros, visto que a sua aparente "masculinização" contribuía para o processo de desnaturalização das posturas do ser homem e ser mulher.

A origem específica da melindrosa é incerta, contudo nossas pesquisas apontam-na como fruto desse sentimento pós-guerra europeu, onde, saídas do recôndito do lar, ganhavam as ruas, ostentando o desejo pelo moderno e pela euforia proporcionada em grandes centros urbanos 
ocidentais. Sua influência desembarcou em diversos países, por meio (entre outros) da imprensa e cinema.

Flapper era a expressão anglofona usada para definir essas jovens com espírito de emancipação, que dançavam, vestiam-se como ditava a moda, além de desafiarem regras, optando viver fora das convenções. Segundo pesquisa de Maria Cláudia Bonadio, uma definição para o termo, encontrada no dicionário Webster New Explores, descreve a garota com esse tipo de comportamento como "[...] jovem mulher dos anos 1920 que demonstra liberdade em relação às convenções e condutas" (BONADIO, 2007, p 132). Outro ponto importante levantado por ela, é a diferenciação entre flapper e a new woman, essa última, muito mais ligada às mulheres envolvidas em lutas políticas e sociais, caso que não nos parece característica principal das flappers e muito menos das melindrosas brasileiras.

A flapper da Inglaterra do pós I Guerra espalhou-se pelos centros urbanos, principalmente por meio dos ascendentes meios de comunicação e transportes. A modernização facilitava que cada vez mais lugares fossem influenciados pelas grandes capitais. Podemos citar o cinema, por meio de Hollywood - os Estados Unidos também tiveram grande parcela de responsabilidade por difundir o estilo pelo globo - e também pela imprensa. Ambos se encarregaram de espalhar da forma mais massiva possível, tendências comportamentais e a moda entre seus influenciados. A modernização dos meios de transporte também deve ser lembrada, visto que, por onde essas moças já influenciadas passavam, serviam como uma espécie de outdoor do estilo, resultando-se em agentes disseminadoras dos hábitos em voga: quem via, e gostava, se apropriava e copiava a sua maneira. As flappers, podem ser consideradas como sinal eminente da forte influência cultural da Europa para com as Américas no início do século XX. A Hollywood dos anos 1920, apresentou numerosas atrizes flappers, esbanjando beleza, sedução e modernidade. "[...] o cinema foi, talvez, a mais óbvia das revoluções 
modernas das comunicações que contestaram os estereótipos e papéis de gênero tradicionais" (BESSE, 1999, p.26). Em Recife, numerosas salas de cinema faziam sucesso entre o público jovem da cidade apresentando essas fitas carregadas de desejos do moderno. Elencamos também a mensagem semiótica propagada por meio das fotografias publicadas em revistas, juntamente aos conselhos de moda e desenhos, todos agentes que aos poucos, foram exercendo sua parcela de influência no que concerne ao molde de novas subjetividades.

$\mathrm{Na}$ França, as garçonnes, - palavra que brinca feminizando o termo garçon - fortaleciam-se. A alcunha foi atribuída, por conta dessas garotas serem consideradas "masculinizadas" principalmente por adotarem a moda dos cabelos curtos. $O$ uso desse termo se intensificou com a publicação do polêmico romance de Victor Margueritte "La Garçonne"2 (SPILBORGHS, 2007, p. 25). As garçonnes dos "anos loucos" franceses, tinham como característica marcante "[...] comportamentos sexuais e sociais extremamente liberais" (BONADIO, 2007, p. 133), fato que também as distinguiam das flappers.

A melindrosa brasileira, figura desvirtuante, "[...] faz estremecer a hierarquização dos sexos, ao mesmo tempo que prega o nivelamento social" (OLIVEIRA, 2002, p.02). Oriunda das camadas médias urbanas, apareceu em vários centros urbanos do país quase que ao mesmo tempo. Seu nome toma emprestado parte da palavra "melindre", que diz respeito à "coisa frágil, delicada", uma mocinha afetada, exagerada nas maneiras de se vestir. Hugo Medeiros (2010, p.107) observa que a melindrosa representava formidavelmente uma mulher armadilha, bela, mas perigosa. Podemos considerar dessa maneira que, a melindrosa configurava-se na "[...] representação de uma jovem elegante, despreocupada e frequentemente frívola" (SPILBORGHS, 2007, p.24), um estilo importado, característico de um período em que o Brasil tornava-se cada vez mais cosmopolita, e que viu-se intensificar com as modernidades que desembarcaram dos EUA e Europa. 
Todas elas tinham em comum a aparência bem trabalhada, os cabelos curtos com cortes "a la garçonne" acabando nas orelhas e com a nuca raspada, a maquiagem forte, as saias pouco abaixo ou mesmo por cima do joelho, os lábios pintados de vermelho carmim e em forma de coração, a indiferença em deixar os braços à amostra, o fato de depilarem as pernas, de desenhar suas sobrancelhas, usarem pequenos chapéus estilo clochê e sapatilhas de amarrar, demonstravam um comportamento diferenciado daqueles que se esperava a uma moça "comum" da época, pois fumavam, dirigiam, dançavam ritmos quentes, andavam frequentemente sem a presença masculina do pai, ou irmão, frequentando chás, magazines, confeitarias, cafés, e festas, além de ousarem lançar flirts insinuando-se aos homens. Comparada a mulher da virada do século XIX, as melindrosas do início do século XX, surpreendentemente distanciaram-se em um curto espaço de tempo. Mario Sette, por exemplo, narra em suas crônicas que as mulheres de sua época, nem sequer saiam às ruas sozinhas! O escritor afirma:

[...] naquela época recuada, bem raras as senhoras que iam fazer compras. O lar ainda tinha um tanto de clausura e nem tudo ficava bonito para "uma mulher direita". O andar de loja em loja era uma dessas ações que não lhe "assentavam". E quando o faziam prescindiam do marido, do pai ou de uma parenta já velha.(SETTE, 1981, p.28-29)

Sette, argumenta que as ruas pertenciam somente às mulheres que não eram "direitas". Era o interdito à liberdade de ir e vir. Levine também aponta em sua pesquisa, como recifenses do século XIX estavam privadas de sua liberdade, restando-Ihes a clausura dos quartos, do lar, sendo incoerente a presença delas nas ruas, muito menos sozinhas:

As mulheres raramente saíam da casa, Segundo um viajante francês do século XIX, a vida da mulher brasileira "alternava entre a janela e a rede". A vida da mulher de classe alta era, todavia, apenas protegida mas não indolente. Ela supervisionava a casa, atendia às emergências do dia a dia, ocupava-se de música, bordado e outras atividades domésticas. Não lhe era permitido ir às compras, as lojas eram escuras e feias. A maior parte das compras ficavam a cargo dos moleques de 
casa e de outros empregados. Uma pequena minoria adquiriu certo grau de emancipação, mas em Pernambuco, durante o Império e no começo da República, isso significava, apenas, o direito de cortar e coser os próprios vestidos e de poder opinar sobre o próprio casamento. (LEVINE, 1980, p.101)

Como podemos observar, a situação das melindrosas distanciava-se das destas mulheres do Século XIX, por aproximarem-se de atividades que outrora lhes eram interditadas. A nova mulher das camadas médias do século XX era assídua nas lojas de roupas e acessórios, andava pelas ruas, e buscava sua individualidade por meio da moda. Susan Besse diz: "[...] enquanto a moda do século XIX havia acentuado a diferença entre os sexos, refletindo seus distintos papéis sociais e a aplicação rígida de um duplo padrão de moralidade, as modas do pós-guerra apagaram subitamente essas distinções." (BESSE, 1999, p.31) A melindrosa era consumidora por excelência, e costumava passear pelas ruas da cidade, fato esse, em Recife, evidenciado pelas revistas de variedades. Entre algumas aparições das personagens, podemos encontrar melindrosas praticando o footing, a ver cinemas, ou ainda frequentando as confeitarias, lojas de produtos variados, sentadas em praças, em jogos de futebol, dançando, etc. O hábito de consumir revistas de variedades também era algo que encontrava-se em voga durante o período pesquisado. Os semanários e as revistas ilustradas eram convidativos à leitura, e além disso, era a oportunidade das moças obterem conselhos, lerem poemas simples, ou até mesmo, se verem flagradas em clicks fotográficos publicadas em suas páginas. A grande diversidade de temas contidos nas revistas pretendia alcançar diferentes públicos leitores, já que era relativamente pequeno o número de pessoas alfabetizadas, e para o sucesso do periódico fazia-se necessário acumular o maior número possível de compradores do impresso (LUCA, 2005 p.121). Essas revistas sugeriam modos de agir, de fazer, de construir sentidos e concepções de mundo. Segundo Mônica Pimenta Vellozo, as formas brilhantes e divertidas 
das revistas comunicavam ao público o que era "[...] ser moderno, como proceder, reagir, pensar e sentir, situando os leitores na correnteza viva dos acontecimentos e na vida mental da metrópole" (OLIVEIRA, 2010, p.81). Os tempos modernos proporcionaram novas sociabilidades às mulheres urbanas. As ruas, antes interditadas a elas, agora Ihes eram lugares em que facilmente eram encontradas. veja o flagrante na imagem abaixo, publicado em Revista da Cidade, Recife, de 1928, no 97.

\section{NAS PÁGINAS DA IMPRENSA}

De maneira diferente da imprensa revisteira, onde encontramos constantemente melindrosas em suas páginas, a impressa jornalística recifense - mais conservadora - reservava pouco espaço para as melindrosas. Entretanto no jornal "A Província" nos deparamos com algumas passagens em que a figura é o foco. Uma das primeiras menções às melindrosas que encontramos, data de 1919 em A Província, que publica matéria extraída da Unided Press, de título "As Mulheres e o Cinema" nela, visualizamos opiniões de algumas personalidades da época acerca do tema. O escultor Louredo Taft exprimindo sua opinião sobre a influência que o cinema exercia sobre as mulheres, afirma ao jornal:

[...] elas admiram as artistas formosas na tela e depois vão para casa prostrar-se diante do espelho horas e horas [...] resulta naturalmente que apuram os movimentos, os gestos, o andar, tornam-se finas, adquirem maior vivacidade [...] todos estes hábitos, poses e especialmente o vestuário característico das artistas exercem muitas vezes uma influência prejudicial e até fatal sobre as mulheres novas. ${ }^{3}$

Como podemos perceber na fala de Louredo, a vida feminina estava se modificando, inclusive na intimidade. Os seus quartos, anteriormente lugares de clausura e interdições, agora se configuravam em quartel general da beleza e do trato: "[...] a vida nos quartos de vestir 
ganhavam novos contornos. Contrariamente às suas antepassadas capazes de passar os dias em roupão branco e desgrenhadas" (PRIORE, 2000, p.65) as moças dos anos 1920 passavam bons momentos dos seus dias copiando modelitos estrangeiros, ora do cinema, ora das revistas, além de imitar suas poses, modo de caminhar, gestos, etc. Na mesma matéria de A Província, citada, encontramos outra opinião, desta vez positiva, defendida por Indiana Gyberson, que argumentou:

[...] o cinema é que está modelando esses tipos admiráveis de beleza natural - os novos lindíssimos tipos americanos [...] no fundo, que é que elas (as melindrosas) imitavam? A rainha do cinema, que estava em moda." ${ }^{\prime 4}$

O cinema estava em momento de auge e incontestavelmente em voga dentro da configuração urbana. "Nessa fase, as representações em torno da figura feminina, muito influenciada pelo cinema norte-americano e suas atrizes de sucesso, colocavam a mulher moderna como esbelta, ágil, combativa, em busca da sua independência" (COUCEIRO, 2003, p. 170). Para Cláudia de Oliveira, contudo, a melindrosa não representava apenas desejos de liberdade, ela era como uma "Eva moderna", que escapa da intervenção divina e torna-se produto mecânico e manufaturado. A melindrosa pode também ser lida como mulher envolta em bovarismo, que parecia ter prazer no poder de ter os homens aos seus pés. Cláudia Oliveira (2010, p.225) observa que de certa forma, essas jovens figuravam escravizadas por uma cultura feminina dependente do consumo e da mercadoria. Para ela, o cinema contribuiu para a construção de uma nova teatralidade feminina, onde ao mesmo tempo em que são reivindicados desejos de liberdade, reafirma-se a mulher como objeto de desejo masculino de paixão e perdição. Era a nova transformação na consciência feminina, que incluía novas possibilidades de exposição e inserção social. Diferentemente das feministas norteamericanas, que usavam muito mais a voz para defender seus direitos, para 
as melindrosas, que aparentemente não estavam diretamente envolvidas com discussões políticas, o corpo é que era a sua arma.

A melindrosa desenvolveu-se longamente, em um processo de modificação que finalmente encontrou aparato para se firmar nos anos 1920. A configuração dos seus corpos, sua ousadia, e a ruptura que ela representava em uma sociedade tradicional, no entanto, foi duramente combatida, principalmente em seus primórdios. Como exemplo, temos uma matéria onde, a colaboradora Cecília de Vasconcellos - sob o pseudônimo de Chrysantheme - do Jornal O Paiz, do Rio de Janeiro, escreve artigo interessante que foi reproduzido na primeira página do Jornal Pequeno de Recife, em 20 de julho de 1920, abordando questões acerca do vestuário feminino, onde mostra-se espantada pela maneira com que a moda vem se transformando nos últimos anos, situação que ela chama de "abolição das saias e dos soutiens gorges." Em sua fala, a Cecília critica as mães mais progressistas, que incentivam as filhas a aderirem modas "escandalosas", que não resguardam os corpos das jovens dos olhares masculinos. Ataca as "[...] senhoras de idade, avós ou mães, acompanhando mocinhas quase nuas, de pernas à amostra até os joelhos" ${ }^{5}$ observando que o instinto materno estaria acabando e a mãe acabara de se tornar "uma cúmplice da falta de juízo da filha" ${ }^{6}$. A colunista continua em sua crítica voltada aos pais dessas jovens, que as liberavam à danças modernas, como ela mesma as chama, em que se fica "[...] tão junto ao par masculino que se esfiapam as frentes dos vestidos"7. Cecilia enfoca a omissão das mães progressistas, que "de pernas cruzadas e face colorida, assistem orgulhadas e impavidamente, ao sem número de olhares de homens que percorrem as pernas, os braços, os colos e os seios de suas filhas, que elas dizem ser donzelas." Era uma afronta à sociedade "descente" e à família. Em A Província, encontramos por sua vez, Alvear de Thales, que comunga com a ideia de Cecilia, também culpando aos pais pela liberdade excessiva dada as suas filhas:"[...] devassos são os pais, que, 
admiram as filhas quando bem decotadas e seminuas, devassas são as filhas, que procuram cativar para os seus corpos no footing [...] os olhares dos semihomens, esses almofadinhas..." ${ }^{\prime 8}$ ambos articulistas escrevem em diferentes jornais, mas similares em seu tradicionalismo. Podemos observar que tanto em A Província, quanto no Jornal Pequeno, os comentários negativos acerca das melindrosas e também aos almofadinhas superavam os que os enalteciam.

“O corpo é, ele próprio, um processo" (SANT'ANNA, 2000, p.09), e como processo, está em constante modificação. É impossível pensar em observá-lo dentro da história de uma única vez e de forma definitiva. Contudo, a modificação de sua apresentação causa geralmente estranhamento entre alguns. A melindrosa é a prova disso. Observando-as como objeto de pesquisa, percebemos como o conhecimento do corpo torna-se interminável e como suas transformações podem percorrer por diversas bases culturais e por lugares sociais diferentes, que por fim, o transformam. Por meio dele, de suas coberturas e comportamentos, as melindrosas expressavam seus desejos de liberdade sobre um corpo que a "[...] sociedade fragmentou e recompôs, regulando seus usos, normas e funções" (PRIORE, 2000, p. 09).

MELINDROSAS, BORBOLETAS, MARIPOSAS...

As mulheres de hábitos modernos receberam diversas denominações pelo globo: flappers, garçonnes, new woman, melindrosas... Em nossas pesquisas também encontramos algumas passagens em que elas eram chamadas de "borboletas, ou até de "mariposas" 9 . Certo que em outros momentos históricos, esses termos tiveram significados distintos, e inclusive foram atribuídos por poetas às prostitutas; contudo as alegorias eram usadas nos anos 1920 com outro sentido. O uso justifica-se perfeitamente pois esses insetos eram belos, trazerem em sua apresentação cores fortes, e por serem Hist. R., Goiânia, v. 19, n. 3, 2014 
atraídas pela luz (vitrines das lojas), equivalem-se, inclusive pelo fato das melindrosas frequentarem muitas flores (homens) levianamente.

Como exemplo, citamos uma passagem em que as moças eufóricas alegoricamente tornam-se mariposas, na pena de Alcides Pimentel, seguem em flagrantes pela cidade:

Ao clarão sumido da tarde, que o sol doira em raios vermelhos de poente, as mariposas adejam pelas ruas, todas inebriadas com as joias ofuscantes das vitrines, ávidas de possui-las, invejosas quase famintas [...] procurando na pilhéria das ruas, nas espeluncas [...] onde queimar as asas... Duas delas confidentes, trocavam futilidades mil coisas de amor [...]: - Os flirts que mantemos com esses rapazes guias de automóveis não são mais que passatempos enganosos que nos arrastam à perdição... [...] - Pois eu gosto. A vida para mim é assim. É preciso gozar a mocidade. Vaira-se, joga-se com a beleza e a elegância.

O bonde parou. Saltaram e separando-se tomou cada uma o caminho da loja. Que mundo, que civilização, que Recife... Na rua o barulho costumeiro das portas de aço que sobem em rolos. ${ }^{10}$

Podemos ver na fala do jornalista, algumas características que essas mariposas traziam. A primeira é o desejo incontrolável de consumir. O desejo pelas joias das vitrines mostra um certo culto pela aparência. Os anos 1920 também são marcados pela influência francesa na moda, e o estilo despojado de Coco Chanel, entre muitas tendências, trouxe de volta os colares compridos. As joias faziam-se importantes como forma de chamar atenção ou ostentar uma posição social diferenciada, entretanto, o excesso delas era mal visto pelos que faziam a moda para a sociedade, tal como descreve Cláudia na Coluna Feminina de A Pilhéria em 1926:

Não há nada mais desgracioso do que uma mulher que dá a impressão de mostruário ambulante, manequim vivo da casa Luiz de Rezende... [...] Além disso, muitas joias juntas sacrificam-se naturalmente umas ás outras e entre tantas, nem uma se sobressai."11

Outro ponto apresentado no relato de Alcides, é a leviandade com os flirts. As moças confessam que adoravam flirtar com os manobristas de automóveis. Juntamente com o footing, o flirt era parte quase que 
indissociável dentro dos hábitos das melindrosas, tal como também era dos almofadinhas. Era um tipo de sensação experimental, volátil. Direcionava-se flirts a muitos de uma só vez. A diversão era mais presente do que o desejo de compromisso, contudo, seria leviano de nossa parte acreditar que não existissem flirtantes que desejassem o casamento.

Outra passagem em que encontramos as moças de hábitos modernos apresentadas ao público como borboletas, aconteceu em uma crônica assinada sob pseudônimo de Crocio Rial, no artigo intitulado borboletas. $\mathrm{O}$ jornalista narra o dia a dia das jovens recifenses por meio de alegoria às graciosas lepidópteras. Vejamos:

[...] existem também borboletas grandes, feiticeiras, tentadoras que passam levemente pelas ruas da cidade, ora aqui, ora acolá, no seu passo incerto e trêmulo, ziguezagueando... De manhã, à tarde, ao sol, os delicados seres joviais e atraentes pululam também pelas lojas e armarinhos, entre aos roseiras das sedas e os tufos de cambraias e cretones. Às vezes porém, cavalos do cão, de calças e paletós horrendos, perseguem-nas numa fúria louca atirando-lhes frases indelicadas, gracejos impertinentes..." ${ }^{\prime 2}$

Aqui mais uma vez, vemos a figura feminina ligada ao consumo de bens de moda, mas também evidenciamos os "cavalos do cão", que pela menção de repúdio aos seus "paletós horrendos", e por lançar gracejos às moças, podem ser eles os famigerados almofadinhas.

As borboletas de Rial são curiosas, ao mesmo tempo unidas por características evidentes às melindrosas: andavam na moda, ansiavam o moderno, adoravam ir às compras, seduziam homens, tinham cabelos à lá garçonne, fumavam, dirigiam, etc. As melindrosas quebraram diversos tabus, como exaustivamente temos apresentado, mas é unanime que sua, digamos assim, marca registrada, foi o corte de cabelo curto. 
AS MELINDROSAS NA ARTE: DESENHOS E LETRAS

A personagem melindrosa viu-se maximizada em suas características e multiplicada em suas singularidades por meio do desenho estereotipado de diversos artistas da época. A sua representação no traçado persistia em intensificar a suas peculiaridades, a sua projeção, isso é característico das charges, onde a intenção de deixar o objeto o mais caricato e pictórico possível, multiplica-lhes os aspectos fundamentais e as características marcantes:

A melindrosa enquanto representação gráfica era uma caricatura da "nova mulher", mas, uma caricatura que realçava primordialmente as virtudes da "mulher moderna", tornando-a ainda mais graciosa e conferindo-Ihe muito mais liberdade do que ela poderia desfrutar na vida prática (DOURADO, 2005, p.99).

As revistas de variedades tornaram-se quase que pequenas galerias de arte, onde artistas expressavam-se por meio de seus desenhos. A melindrosa consolidava-se como uma de suas figuras preferidas. A Pilhéria, é também a que mais encontramos melindrosas e almofadinhas. Talvez por ser uma revista que tinha como ideia inicial ser voltada para o humor, os editores:

[...] falavam de melindrosas e almofadinhas não só porque boa parte dos(as) leitores(as) se enquadrava nestas categorias - ou conhecia pessoas que se enquadravam - mas, e não menos importante, porque estas eram figuras faziam rir a cidade com seus trejeitos modernos (MEDEIROS, 2010, p.99).

Por fazerem-se rir, a exploração caricata das belas moças era mais do que comum. Na maioria das capas de $A$ Pilhéria, encontramos desenhos que as representavam em situações cotidianas. Mas não foi somente nesse semanário, também encontramos em alguns jornais e outras revistas. No que concerne a representação pictórica da moça moderna, segundo o cronista Álvaro Moreyra, é dado à criatividade do carioca J. Carlos o título de "inventor" da melindrosa(MOREYRA, 1991, p.28). Sua importância 
é notável. Outros artistas por todo Brasil presentearam a posteridade com desenhos de suas flappers girls, inclusive chargistas pernambucanos como Zuzu (pseudônimo de José Borges da Silva) e Jota Ranulpho, que colaboraram em algumas publicações em Recife, inclusive em A Pilhéria. Abaixo elencamos algumas capas em que os editores de $A$ Pilhéria usaram do artificio da arte manual, retratando melindrosas e almofadinhas. A Pilhéria № 205, de 1925; no 256 de 1926 e a 267 também de 1926.

A apresentação da melindrosa por meio do desenho tinha semelhanças em todos os artistas: traços soltos, simbolizando a leveza, mas também esboçavam sensualidade com o olhar. Eram mocinhas ingênuas, mas basta observar seus lábios grossos e em forma de coração para sentir o ar de indiferença misteriosa, que atrai. A ambiguidade é o predicado mais presente nas ilustrações das melindrosas. Importante ressaltar que, juntamente à figura da moça moderna, encontramos geralmente um almofadinha - ainda mais caricato - com cara de bobo, pelas sombras de sua contraparte.

As letras denunciavam a presença das melindrosas. Em poemas ou versinhos publicados nas revistas que pesquisamos, muitas vezes não assinados, percebemos o quanto a personagem estava em foco, e como essas mulheres mexiam com a cabeça dos homens. Os versos lidos em grupos de moças ao redor de semanário durante o chá das 5, acalentavam seus egos, massageavam-nas quando as exaltavam, e serviam de inspiração para novos charmes e peraltices. Para Chartier a prática da leitura é uma atividade produtora de sentidos, de significados, que não se reduzem as intenções dos autores, mesmo que esse mesmo autor, comendador ou editor, pense na sujeição do leitor e na compreensão de um único sentido na leitura de seu texto (CHARTIER, 2002, p.123). Desta forma, os poemas falavam de melindrosas, atribuindo-lhes os mais diferentes significados e características. Versos que deixam o/a leitor/a sujeito a interpretações plurais e até mesmo absolutamente opostas, como o exemplo abaixo: 
Linda garota irônica e endiabrada

como é que, ainda tão menina e tão trelosa,

já te fazes tão notada,

tão requintada

melindrosa ${ }^{13}$

A pena do autor deixa o público leitor livre para sua própria interpretação. Ora, o admirador da "requintada" melindrosa, ao ler sobre as suas peraltices e da beleza da moça, pode se fascinar facilmente, despertar o desejo de estar perto, de tocar, de sentir a melindrosa; como, por outro lado, o que a repudia, a verá como moça "endiabrada", menina de melindres, as trelas das jovens beiram a imaturidade e irresponsabilidade. Interprete como quiser.

E eis a encruzilhada que estava situada a mulher das camadas médias urbanas dos anos 1920: entre a moderna mudança de costumes e apresentação ou estacionada no tempo, mantenedora das tradições. Entre os defensores ainda subdividiam-se os que apoiavam a manutenção dos hábitos modernos, mas que se permanecessem a feminilidade, e a submissão em nome da família. "[...] esperava-se que as mulheres cultivassem uma aparência exterior de sofisticação moderna, e ao mesmo tempo conservassem as "eternas" qualidades femininas de recato e simplicidade." (BESSE, 1999, p.40) O fato é que, mesmo com a resistência, encontramos em fotografias evidencias que a moda dos cabelos curtos, das roupas mais leves, dos sapatos de amarrar, da maquiagem foi pouco a pouco sendo assimilada pela população em geral, chegando a um ponto em que deixou de ser vista com estranhamento, ao mesmo tempo em que, pouco a pouco, as mulheres modernas cessaram de ser chamadas de melindrosas. Os cabelos curtos gradativamente deixavam de ser tendência, voltando à moda os cabelos compridos. Já durante a década de 1930 as aparições das melindrosas diminuem consideravelmente nos documentos da imprensa, 
sobrando-lhes apenas aparições esporádicas no mês de fevereiro, em meio às folias de momo, geralmente como fantasia da festa.

\section{NotAs:}

(Endnotes)

1 Outra figura de extrema relevância no universo dos anos 1920. O almofadinha andava pelas sombras das melindrosas, bem vestidos, com ternos engomados, eram rapazes modernos, que aos poucos foram criando também um estilo próprio. Os almofadinhas lançavam olhares, cortejavam, atreviam-se a dançar os mais diversos estilos (coisa impensável a um homem comum da época) o momento da dança era a oportunidade ideal para um bom flirt com uma melindrosa.

2 No Brasil foi lançado com o título adaptado "A Emancipada".

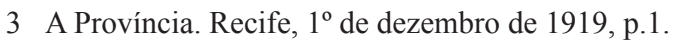

4 A Província. Recife, $1^{\circ}$ de dezembro de 1919, p.1.

5 Jornal Pequeno, Recife, 20 de julho de 1920, p 1.

6 Jornal Pequeno, Recife, 20 de julho de 1920, p 1.

7 Jornal Pequeno, Recife, 20 de julho de 1920, p 1.

8 A Província, Recife, 28 de setembro de 1924, p 7.

9 Conforme destaca Hugo Augusto Vasconcelos Medeiros em sua tese: Amores de ontem, amores de outrora (ver referencias) e confirmado em A Pilhéria, Recife, 1927 nº 296.

10 A Pilhéria, Recife, 1927, n 296. (obs: as publicações de $A$ Pilhéria não possuíam páginas numeradas.)

11 A Pilhéria, Recife, 1926, nº 245.

12 A Pilhéria, Recife, 1920 n $^{\circ} 202$

13 A Pilhéria, Recife, 1924 nº 153.

\section{REFERENCIAL}

\section{Revistas:}

A Pilhéria, Recife, 1920 no 202.

Hist. R., Goiânia, v. 19, n. 3, 2014 
A Pilhéria, Recife, 1920 no 205.

A Pilhéria, Recife, 1924 no 153.

A Pilhéria, Recife, 1926, № 245.

A Pilhéria, Recife, 1926, no 256.

A Pilhéria, Recife, 1926, ㄲo 267.

A Pilhéria, Recife, 1927, № 296.

Revista da Cidade, Recife, 1928, no97.

(Fundação Joaquim Nabuco, Recife - PE: http://www.fundaj.gov.br/)

Jornais:

A Província, Recife, 28 de setembro de 1924.

A Província. Recife, 10 de dezembro de 1919.

A Província. Recife, 1o de dezembro de 1919.

Jornal Pequeno, Recife, 20 de julho de 1920

(Hemeroteca da Biblioteca Nacional, Rio de Janeiro - RJ: http:// hemerotecadigital.bn.br/)

\section{Bibliográfico}

BESSE, Susan K. Modernizando a desigualdade: Reestruturação da ideologia de Gênero no Brasil 1914-1940. São Paulo: Edusp, 1999.

BONADIO, Maria Cláudia. Moda e sociabilidade: mulheres e consumo na São Paulo dos anos 1920. São Paulo: Editora Senac, 2007.

CHARTIER, Roger. A História Cultural: entre práticas e representações. 2aㅡ Edição, Lisboa: DIFEL, 2002.

COSTALLAT, Benjamim. Mademoiselle Cinema. Rio de Janeiro: Casa da Palavra, 1999.

COUCEIRO, Sylvia. Costa. Artes de Viver a Cidade: Conflitos e convivências nos Espaços de Diversão e Prazer do Recife nos Anos 1920. [tese] Recife, Universidade Federal Rural de Pernambuco, 2003. 
DOURADO, Rosiane de Jesus. As Formas modernas da mulheres brasileira: décadas de 20 e 30 do século XX [dissertação] Rio de Janeiro: Pontifícia Universidade Carioca do Rio de Janeiro; 2005.

FRANÇA, Patrícia de Souza. Livros para leitores: a atuação de Benjamin Costallat para a ampliação do público leitor no Rio de janeiro dos anos 20. Rio de Janeiro: Fundação Biblioteca Nacional, 2010.

LEVINE, Robert. A velha usina: Pernambuco no Federação Brasileira 1889 1937. Rio de Janeiro: Paz e Terra, 1980.

MEDEIROS, Hugo Augusto Vasconcelos. Amores de ontem, amores de outrora: emoção e Gênero no Recife dos anos 1920 e 1930. [dissertação] Recife: Universidade Federal Rural de Pernambuco, 2010.

MEDEIROS, Hugo Augusto Vasconcelos. Melindrosas e Almofadinhas: Relações de Gênero no Recife dos anos 1920. Revista Tempo e Argumento, UDESC volume 02 número 02 jul/dez. 2010.

MOREYRA, Álvaro. A Cidade Mulher. Rio de Janeiro: Biblioteca Carioca, 1991.

OLIVEIRA, Cláudia de; VELLOZO, Monica Pimenta; LINS, Vera. O moderno em revistas: Representações do Rio de Janeiro de 1890 a 1930. Rio de Janeiro: Gramond, 2010, p 225.

OLIVEIRA, Iranilson Buriti de. educando pela roupa: a educação do corpo através da moda no Recife dos ano 20. Anais do I/ Congresso Brasileiro de História da Educação. Natal, 2002

PERROT, Michelle. Minha história das mulheres. São Paulo: Contexto, 2007.

PRIORE, Mary Del. Corpo a corpo com a mulher: pequena história das transformações do corpo feminino no Brasil. São Paulo: Senac, 2000.

RODRIGUES, Marly. O Brasil na década de 1920: Os anos que mudaram tudo. São Paulo: Ática, 1997.

SANT'ANNA, Denise Bernuzzi (org) Políticas do Corpo. São Paulo: Estação Liberdade, 2005.

SCOTT, Joan Wallach Gênero: uma categoria útil de análise histórica" Revista Educação \& Realidade. Porto Alegre, vol. 20, no 2, jul./dez. 1995. 
SETTE, Mário. Maxambombas e Maracatus. Recife: Fundação de Cultura Cidade do Recife, 1981.

SEVCENKO, Nicolau. O prelúdio Republicano, Astúcias da Ordem e Ilusões do Progresso. In SEVCENKO, Nicolau; NOVAIS, Fernando A. (org) História da Vida Privada no Brasil vol 3. São Paulo: Companhia das Letras, 1998.

SPILBORGHS, Mariana Alza. Moda, beleza e sociedade: um estudo da ilustração no Brasil através da revista "Careta", 1920 e 1950. [trabalho de conclusão de curso] Florianópolis, Universidade do Estado de Santa Catarina, 2007.

LUCA, Tania Regina de. História dos, nos e por meio dos periódicos. In:PINSKY, Carla Bassanezi (Org). Fontes Históricas. São Paulo: Editora Contexto, 2005. 
